\title{
El secreto de Vitoria y sus silencios
}

\author{
"Podría pensarse desde un principio que \\ todo este trabajo es inútil y trivial", \\ Francisco de Vitoria "De Indis" sección 1.
}

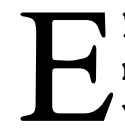
1 propósito de mi trabajo consiste en explorar algunos de los diferentes modos bajo los cuales el indio está siendo definido y construído en varios textos teológicos, políticos y legales en términos de su relación con instancias de poder dentro de las instituciones y prácticas discursivas del estado moderno.

Este proyecto entraña una reevaluación de la obra de Vitoria a la luz de los actuales debates en tomo al conocimiento, la representación y la construcción de identidad en el estado moderno. Dentro de este marco general, voy a enfatizar las tensiones, contradicciones, dudas y vacilaciones de Vitoria como síntomas de los conflictos en los que se haya la moral y el pensamiento político del Renacimiento.

Mi intención es sostener que los textos jurídicos y teológicos de Vitoria crean un Nuevo Espacio Ontológico dentro del cual el indio está siendo construído y que la construcción de ese nuevo espacio corresponde de manera directa a la necesidad institucional de legitimación de la empresa colonizadora. Lo que propongo, entonces, es un análisis textual en el cual sondearé varios textos para encontrar esos silencios, vacíos, tensiones y contradicciones en la obra de Vitoria que expresan la naturaleza conflictiva del Nuevo Espacio Ontológico.'

El ensayo consistirá en tres partes: en la primera pretendo mostrar cómo la obra vitoriana está fundamentada en la Teología Tomista. Vitoria está tratando de construir un "Sistema" en teología al igual que Santo Tomás lo hizo. La segunda parte describirá cómo funciona el Nuevo Espacio Ontológico. La tercera va a estar dedicada al análisis textual, centrándonos en mostrar principalmente, cómo la entidad "Indio" afecta las instancias políticas, jurídicas y teológicas 
en el Siglo XVI. ${ }^{2}$ Como conclusión me gustaría sugerir unas líneas de investigación que dirigieran su esfuerzo a la reevaluación del pensamiento de Vitoria en el marco contemporáneo del debate acerca del funcionamiento del Estado moderno, así como la naturaleza de sus instituciones y sus redes de poder. ${ }^{3}$

La obra de Vitoria está basada en St. Tomás. Teófilo Urdanoz y Lewis Hanke, dos de los más dedicados analistas de los textos de Vitoria, coinciden en juzgar al dominico como fundador del Orden Jurídico Internacional Moderno y "Padre del Renacimiento Español al Tomismo".4 Sus "Relecciones Teológicas" constituyen el primer Tratado Judicial Moderno en la Historia y es sabido que fueron escritas para responder a las cuestiones originadas por la complejidad de las relaciones entre el Viejo y el Nuevo Mundos. La estructura de las "Relecciones" sigue exactamente la misma de la Summa Teológica de St. Tomás, dividiendo el texto en cuestiones, artículos y argumentos teológicos de autoridad. De hecho, como catedrático de la Universidad de Salamanca desde 1526, estuvo a cargo de la cátedra de "Summa" hasta el momento de su muerte. De esta manera, el principal argumento de autoridad en la obra de Vitoria es St. Tomás. El dominico tratará de construir su "Sistema Teológico". De acuerdo con Hanke, esta fue la intención general de todo autor en el Siglo XVI: "España se convirtió en el Siglo XVI en el foco de los escolásticos" amantes de sistematización, precisión y teología. Hanke cita a Roberto Blakey para explicar el desarrollo de la teoría política y teológica con estas palabras:

"No hubo país en Europa en que la política, como ciencia, experimentara investigación y escrutinio más general [...] que en España. [...] Encontramos muchos tratados sólidos sobre los principios abstractos de gobierno, que dan muestras de una libertad de examen y de un grado de talento y saber que, honrarian a cualquier país.[...] Y nos atrevemos a afimar que en ninguna parte de las especulaciones humanas se ha manifestado más habilidad lógica en el disponer y más capacidad en el manejar principios generales que en las obras científicas de los españoles sobre política y jurisprudencia. [...] Todas estas disquisiciones políticas poseen un carácter distintivo. Todas ellas tratan de política a través de la revelación cristiana. [...] Este enfoque teológico impreso sobre todas las disertaciones españolas acerca de cuestiones políticas, arrancó de la grande y predominante influencia de St. Tomás de Aquino"."

Pero, lejos de lo que puede ser pensado dentro del marco de la Teologia Tomista, Vitoria, siendo puro hombre renacentista, incorpora en su obra diferentes escuelas de pensamiento, desde San Agustín hasta Pedro Lombardo, pasando por Ockhan, Duns Scoto...; de modo que en palabras de Urdanoz "(Vitoria) se aleja tanto de Santo Tomás hacia el nominalismo y hacia el posterior Molinismo que luego ha de ser rectificado por los teólogos tomistas". En efecto, Urdanoz llega a defender que se haya más cerca de posturas Humanistas que de St. Tomás mismo. 
Dicho esto, quiero sostener que el sincretismo de Vitoria implica un enorme esfuerzo para elaborar una síntesis teológica última que responda a las cuestiones fundamentales traidas a la luz por la modernidad. Las vacilaciones de Vitoria son el reflejo de la confusión general que reinaba en la Teología del Renacimiento. Desde los seguidores de las "Sentencias" de Pedro Lombardo, hasta San Agustín, Ockhan, Erasmo, Luis Vives... el pensamiento Teológico y juridico del Renacimiento incorpora tan magna cantidad de conflictos que resultan en Sistemas omniexplicativos contradictorios con el fin de regular la relación entre Dios y hombre, señor y vasallo, Iglesia y feligreses; entre el Rey y sus Súbditos, entre el cristiano y el no cristiano, en el mundo modemo. El dominico, en medio de todos estos diferentes sistemas de pensamiento, se aplica en crear las líneas generales que supusieran la síntesis última de la Teología cristiana y, dado que no puede reconocer las contradicciones entre estos autores, intenta mediar sus posiciones con el fin de legitimar las bases teoréticas de la empresa colonizadora. Así, mientras en las páginas 1338 y 1339 toma la posición de Ockhan: "no es necesario para que el acto sea moralmente bueno que se refiera (o conozca) a Dios, 1d. 1q. 1" ?. Varias páginas más tarde, exactamente 1351, vuelve a la ortodoxia tomista: si las obras no se refieren a Dios no sólo no son buenas, sino que son pecados, "Dios es el Principio para conocer el Bien y el Mal". ${ }^{8} \mathrm{De}$ manera obvia estas dos últimas sentencias son contradictorias; sin embargo el secreto de Vitoria descansa precisamente en el reiterado intento de esconder su contradicción inherente.

A mi parecer, las mayores tensiones en la teoría de Vitoria se reflejan en los siguientes puntos: el problema del uso de razón, el problema de la naturaleza del indio, y la cuestión de cuándo es permitida la intervención armada, o en otras palabras, cuándo es una guerra justa.

Dado esto, me gustaría explicar cómo el concepto de uso de razón en Vitoria crea el Nuevo Espacio Ontológico en el cual la Conquista será legitimada. Siguiendo la Teología de St. Tomás se nos presentan dos diferentes espacios: por un lado, el espacio del hombre Occidental que es capaz del uso de razón, o lo que es lo mismo, que puede pensar racionalmente. Para el angélico cuando el hombre usa su razón inmediatamente conoce la fe, y dirige sus acciones a Dios, consiguiendo la salvación. Así, según la deducción lógica que se sigue del planteamiento, ejercitar el uso de razón supone conseguir la salvación. De otro lado, él define un segundo espacio en el que estarían los sabios sin moral, personas doctas que practican la ciencia pero que anómalamente no saben cómn actuar en el campo de la praxis moral; los niños, y los dementes o mentalmente incapacitados. Dentro de este espacio no usar la razón supone la imposibilidad de conocer a Dios.

Dentro de este marco, Vitoria crea el Nuevo Espacio Ontológico para el recién descubierto salvaje. El indio, el salvaje, tiene uso de razón y por lo tanto 
está justificado en sus acciones cuando actúa de acuerdo con la ley natural; en otras palabras, el indio no necesita conocer a Dios para discriminar entre el Bien y el Mal y por la misma razón es capaz de practicar el Bien y actuar de manera moralmente justificable. A mi modo de ver lo que Vitoria está haciendo es abrir un Espacio Ontológico intermedio donde los dos espacios de St. Tomás puedan mediar: "todo hombre que llega por primera vez al uso de razón, aunque no conozca ni pueda conocer a Dios, puede obrar el bien". 9

A partir de aquí la argumentación de Vitoria se hace farragosa y oscura, a veces cuesta trabajo distinguir en qué se separa su posición de los argumentos de autoridad..$^{10}$ Lo que aparece claro es que se intenta crear el ámbito ontológico del salvaje en el contexto de su actuación moral. El salvaje puede actuar moralmente y practicar el bien sin conocer a Dios (es decir sin ordenar su acción a Dios), ya que el libre albedrío es una facultad del entendimiento y de la voluntad. Vitoria arguye la diferencia existente entre ley natural y ley divina; derecho natural y derecho positivo divino, siguiendo en esto la doctrina tomista que demarcaba como distintos los campos de la fe y de la razón. El salvaje obra conforme al derecho natural y está excusado como San Pablo excusa al ignorante:

“¿Cómo invocarán aquel en quien no creen? Luego, si no hay culpa en no creer, como ya se ha probado, tampoco la habrá en no invocarle o en no referir a Dios las obras [...] además parece inicuo y contra la bondad de Dios decir que le ofende el que menos piensa en ofenderle y que sin embargo, nadie puede obrar bien si no se esfuerza en agradarle dirigiendo a $\mathrm{El}$ actualmente sus obras"."

Sin embargo al final de la cuestión séptima, segunda parte de la relección, Vitoria añade que el que los salvajes sean justificados y reciban la gracia mediante ese acto de conversión al bien honesto, es ordenación implícita a Dios. (Téngase en cuenta que en St. Tomás cuando razón y fe no alcanzan de igual manera el mismo propósito, es decir Dios, es por un error de la razón $\left.{ }^{12}\right)$. Lo que prueba que Vitoria sabía de los problemas a los que podía llegar con su interpretación del uso de la razón anclado en el entendimiento y la voluntad. Así, fruto de su continua vacilación en aceptar el texto tomista, desemboca diciendo que "Dios, es el principio para conocer el bien, y el mal", luego, la razón por sí sola no puede ser el principio de la moral.

"Más la razón humana no tiene fuerza para obligar ni razón de ley si no es por la ley divina... [pues] toda potestad viene de Dios". ${ }^{13}$

Vitoria se ve incapacitado para conferir la autonomía a la razón (tendremos que esperar hasta Kant en el siglo XVIII) pudiendo discurrir racionalmente el bien del mal, ya que eso tendría como consecuencia justificar las acciones de los salvajes sin tener un conocimiento de Dios, lo cual no justificaría la conversión 
y la violencia. Por lo tanto, se termina diciendo: si no hay fe, no hay salvisción. Hay que imponer la fe para que se salven.

En este sentido, irónicamente, incluso cuando la omnipresencia de Dios es evidente en el salvaje, ya que Dios es evidente y no se necesita mucho tiempo para conocerle, el infiel no puede alcanzar la salvación sin la intervención de un agente iluminador externo que se la garantice. De este modo, si al principio el dominico hacía suyas teorias humanistas y voluntaristas por las cuales el salvaje está siendo considerado un ser completamente racional capaz de lo bueno en el orden moral de la ley natural, al final va a mantener que la única vía para que el alma del salvaje sea redimida y se salve, pasa por la aceptación de la fe cristiana. Vitoria, con esta teoría, no sólo ofrece una justificación cristiana para la intervención de los españoles en el Nuevo Mundo, sino que simultáneamente demarca y defiende un lugar central para una correcta Teología que preserve tanto los derechos del indio como aquellos de la corona española.

"Oímos hablar de tantas muertes de hombres, tantas expoliaciones y privación de posesiones de hombres inofensivos, en todo lo cual hay razón para dudar si se han hecho estas cosas con justicia o injuria". Todo esto hay que verlo a la luz de la Teología. Son "cuestiones de conciencia" en que los ministros de la iglesia tienen la decisión ya que estos negocios "han de ser examinados por las leyes divinas más que por las leyes humanas" defendiendo que las leyes divinas tienen primacía sobre las leyes humanas ${ }^{14}$.

Particularmente considero que la creación de esta mediación fue el único modo de justificar la intervención de las instituciones de la iglesia y del Estado ofreciendo la legitimación teológica para la conquista y la colonización del nuevo mundo.

¿Qué piensa Vitoria de la naturaleza del salvaje? la naturaleza del indio tiene que ser redefinida dentro de los límites de este intermedio espacio ontológico, y para tal propósito Vitoria, lejos de escoger el concepto tomista de bárbaro, el cual le llevaría explícitamente a justificar la esclavitud de la población indígena sirviendo a propósitos educacionales ${ }^{15}$, adopta la teoría aristotélica de la potencia y el acto (potentia/actus) para definir al bárbaro como un niño que necesita ser guiado a su perfección, lo cual no es otra cosa que la salvación en Dios.

Vitoria desarrolla toda esta problemática a lo largo y ancho de su relección: "de la obligación de convertirse a Dios al llegar al uso de razón" y principalmente en la tercera parte de la relección, cuestión tercera, número catorce, donde se plantea el problema de la salvación del niño salvaje; así como en la parte segunda, número uno, donde se trata con toda urgencia el problema del niño educado en la barbarie y sin conocimiento de Dios.

"Siguiendo a Cayetano sostiene el maestro que "el niño no está obligado a convertirse a Dios explícita y formalmente" ( $\left.\mathrm{N}^{\circ} 12\right)$, sino que el precepto se 
satisface con la simple conversión al bien honesto (denvado del uso de razón), que es al mismo tiempo conversión implícita a Dios. Se trata sólo del niño no bautizado y sin conocimiento distinto o expreso de Dios"6

En cambio, juzga Vitoria que ninguno de estos infieles, así justiticados, recibirán la salvación eterna sin el conocimiento explícito y la fe en Jesucristo. Como veremos más adelante, las dudas que le asaltan en este punto de la conversión al bien honesto derivado del uso de razón, enfrentándolo frontalmente a St. Tomás para el que no existe justificación moral si no es dentro de la fe, le conducirán irrevocablemente a que silencie su Cuarta relección "sobre la cuestión principal" en la que no se trata ya de la obligación o no del niño de convertirse a Dios, sino de si al hombre al llegar al uso de razón le queda abierto el camino para la salvación y la vida etema. Es decir, de los medios de salvarse que tienen los hombres fuera de la iglesia. Como ya he dejado dicho, al final de su tercera relección "de aquello a que está obligado el hombre al llegar al uso de razón", la vuelta a St. Tomás se hace manifiesta para defender a la iglesia como agente ilustrado que guía al niño salvaje hacia su salvación. Otro ejemplo de pensar al bárbaro como un niño (polluelo, en este caso) lo ofrece Lyle $\mathrm{N}$. McAlister como sigue:

"All these Indians are like nestlings whose wings have not yet grown enough to allow them to fly themselves..." The missionaries, he continued, "are their true fathers and mothers, their advocates, and representatives, who take for them all the blows of adversity..."17

[Todos estos indios son como pulluelos cuyas alas aún no han crecido lo suficiente para permitirles volar por sí mismo" los misioneros, continuaba "son sus verdaderos padres y madres, sus abogados y representantes, quienes cuidan de todos ellos frente a toda adversidad"]

Quede claro, en este punto, que no estoy interesado en un supuesto mensaje autorial en términos de la intencionalidad de Vitoria, sino más bien tratar de vislumbrar de una parte la coherencia significativa y de otra las vacilaciones de los textos en términos de la encrucijada teológico legislativa que se presenta al Estado Moderno español en función del proceso colonizador. A mi modo de ver, la encrucijada se plantea en los siguientes términos:

1. El indio sin alma. Postura defendida por Sepúlveda y por aquellos que necesitaban la exclavitud de los indios para favorecer sus intereses particulares. Para Sepúlveda el salvaje es un "homúnculo" incapaz de conseguir la salvación y por lo tanto una bestia que tiene que ser castigada. Si el indio no tiene alma la empresa evangelizadora está injustificada. Los indios son bestias, no tienen derechos, hay que esclavizarlos sin más y no hay que preocuparse por hacerlos súbditos libres de la corona.

2. El indio como hombre con conocimiento de lo que sea el bien y el mal, es 
decir, hombre en el que la acción está justificada sin la fe: esto tampoco justifica la inkervención de los españoles en principio. A esta postura llegó en más de una ocasión Las Casas en su desaforada defensa del Indio como ser racional y completo, con la intención manifiesta de que llegara a formar parte de la corona en calidad de súbdito. No en vano Las Casas ha sido considerado el más famoso defensor de los indios.

3. Vitoria: define un espacio intermedio. El indio es un niño que ha de ser educado en la fe para salvarse. Vislumbra la razón, pero no tiene fe; por lo tanto su razón no es completa. El indio es el "vacio" que existe entre el hombre y la bestia; siguiendo a Aristóteles, un ser que no es todavía hombre y que necesita ser dirigido a su fin o a la perfección que le es propia, constituirse como hombre para salvar su alma en Dios. Esta será la única posición que justifique plenamente tanto la Evangelización como la intervención pacífica en el nuevo mundo'. Las Casas se hará eco de ella para luchar contra Sepúlveda en los debates de 1550-1551, en los términos planteados por el "doctísimo Vitoria" y al final sería esta defensa del indio lascasiana la que saldrla airosa ante teólogos, Reyes y Papa. Por otra parte, Vitoria ha sido conectado con corrientes humanistas, en términos cercanos a Ockham, Molinos o Vives, en los que las obras producen salvación. El Concilio de Trento, haciéndose cargo de la aporía irreductible consecuencia de no casar fe y razón, resolverá, volviendo a postura tomistas, que es imposible la salvación si las acciones no son asistidas por la fe y referidas a ella. Esto marcará el posterior curso del catolicismo y el protestantismo.

Ha llegado el momento de exponer por qué las teorías de Vitoria no fueron suficientemente estimadas durante su vida, y sólo vista su importancia hasta finales del siglo XIX y principios del XX.

Primeramente hay que decir que sus principales relecciones nunca vieron la luz por el simple hecho de que nunca fueron escritas. Así, la cuarta relección "de la obligación de convertise a Dios al llegar al uso de razón" o como él mismo la llama "sobre la cuestión principal" no fue escrita; del mismo modo, no realizó la última parte "de indis" sobre las cuestiones más importantes teológicojurídicas acerca de la ética de la administración colonial, siendo esta la obra que le ha lanzado a la gloria de ser el fundador del Derecho Internacional Moderno. El dominico anunciaba en sus clases que iba a hacer el trabajo pero nunca lo hizo. Desde mi punto de vista, Vitoria cayó en un impasse derivado de sus tensiones que provienen de su misma perplejidad en tomo a la doctrina que va a exponer. En opinión de Beltrán de Heredia (uno de los más dedicados estudiosos del pensamiento del dominico): Vitoria no escribía las últimas partes de las relecciones "temiendo complicaciones" de los poderes públicos, al estar dudando sobre el Derecho español en la conquista de América". Así se puede suponer que sus conclusiones prácticas sobre la libertad y trato humano de los indios fueran en exceso duras y contrastaran demasiado con la realidad de lo que suce- 
día en America y con las opiniones corrientes, por lo que podía chocar e inquietar aún más en la corte. De hecho desde 1539 Carlos V comienza a establecer un intercambio de cartas con Salamanca (y por supuesto con Vitoria, una vez concretamente sobre el bautismo de los naturales) haciendo consultas concretas sobre la evangelización de las indias ${ }^{20}$. En varias de ellas expresa el daño que puede causar a la iglesia y a la corona la actuación desacertada en Indias ${ }^{21}$. Sea como fuere, Vitoria no escribió lo que intentaba responder a las preguntas enmarcadas en los cuatro problemas básicos.

- Si al hombre al llegar al uso de razón le queda abierto el camino para la salvación y la vida eterna, ¿Qué necesita este hombre para salvarse?

- ¿Qué principios deben informar la política seguida con respecto a los indígenas?

- ¿Qué normas deben establecerse para la política económica colonial? -y quizá más importante para nosotros- ¿Con arreglo a qué principios ha de procederse en la obra de evangelización?

Muchos de los tratados jurídico-teológicos posteriores a Vitoria sufrirán de esta falta a causa de la propia omisión vitoriana. Estas omisiones representan los vacios y vacilaciones que nuestro autor tenía en materia teológica y jurídica con respecto al nuevo fenómeno indio en el marco más amplio de la realidad del Nuevo Mundo. Realidad descubierta que ponía en jaque las estructuras estamentales medievales, y a la que había que asistir con una renovación teológicojurídica a la altura de las necesidades demandadas por la empresa en el Estado Modemo ${ }^{22}$.

Efectivamente, esta época está llena de conflictos de intereses; de contradicciones, de confusión, de teologías al servicio del poder, de luchas intestinas entre sectores de la iglesia y sectores civiles, de odio, de mala fe, de mentiras; de violencia atroz.

Valgan como ejemplo algunos de los comentarios siguientes. Así, mientras Las Casas se hacía eco de la bandera del pacifismo en la intervención de indias sosteniendo que todo hombre es libre y tiene derecho a gobernarse por sí mismo, con el claro propósito de hacer súbditos de la corona a los indios, defendía al mismo tiempo la esclavitud de los negros nacidos en España, siendo uno de sus remedios que éstos y otros exclavos trabajaran las minas en lugar de los indios. Incluso cuando al final de su vida "se retractó" de que los negros tenían que ser esclavos, nunca los vio como iguales y siempre privilegió a los indios. Por otro lado señala Hanke que mientras para escribir su Apologética Historia (15271547), dónde defiende a los indios como superiores siguiendo la clasificación de Aristoteles en lucha contra Sepúlveda, en 1519 opinaba del estagirita que era: "un gentil y está ahora quemándose en el infiemo"23. De este modo, el filósofo 
clásico servía a dos intereses en el mismo debate, los de Las Casas y los de Sepúlveda, cosa extraña pero cierta si sus ideas eran mediadas por el cristianismo. Por otro lado, es interesante saber que 40 años antes del descubrimiento en 1452 y 1454 se defendía la conquista y la guerra de acuerdo a dos bulas papales basadas en el Naturalismo Agustinista (el cual después veremos cómo influye en Vitoria). El conflicto de intereses era tan grande 24 que monjes y clero peleaban entre si ${ }^{23}$. Además vemos cómo las diferentes órdenes cometían abusos como el de los franciscanos que bautizaban a miles de indios en un día por aspersión, siendo criticados por Dominicos y Agustinos que resuelven que: "no se les bautice antes de ser debidamente instruidos en la fe y costumbres cristiana y parezca verosímil que entienden lo que reciben y profesan en el bautismo"26. Baste para terminar decir que el requerimiento era todavía leído en 1697, como apunta Hanke ${ }^{27}$, y que si por un lado se luchaba para defender la humanidad del indígena, por otro se dice que:

“...Gonzalo Fernández de Oviedo described the natives he saw on Española and tierra firme as "naturaly lazy and vicious, melacholic, cowardly, and in general a lying, shiftless people... [But] what could one expect from a people whose skulls are so thick and hard that the spaniards had to take care in fighting not to strike on the head lest their swords be blunted?" Teaching the christianity, he observed ironicalley, "is like chewing on a cold piece of iron"28.

[Gonzalo Fernández de Oviedo describió a los nativos que vio en Española y tierra firme como "naturalmente haraganes y viciosos, melancólicos, cobardes $y$, en general gente mentirosa e inútil... [pero] qué se podría esperar de gente cuyos cráneos son tan gruesos y duros que los españoles tienen que tener cuidado en combate de no golpearlos a menos que deseen ver sus espadas amuinadas?" enseñarles el cristianismo, observaba irónicamente, "es como mascar un pedazo de hierro sólido"].

Es verdad que Vitoria estuvo en silencio la mayor parte de su vida, y que sólo se dedicó a sus deberes académicos, pero también es verdad que sus continuas ambivalencias y dudas hacen e hicieron a su trabajo oscuro incluso para sus contemporáneos. Efectivamente, Sepúlveda nunca mencionó en Valladolid a Vitoria y Las Casas sólo lo hizo una vez llamándolo, "doctísimo maestro" en toda la disputa, cuando la influencia nos pudiera parecer obvia. Para Philip Means Las Casas se ha llevado todo el crédito que Vitoria deberia haber recibido $^{29}$.

Lejos de esta polémica, la consecuencia de la teoría de Vitoria es clara: para que el indio sea libre y legal dueño de su tierra, así como para que sea capaz de alcanzar la salvación, tiene que hacerse súbdito de la corona española. En términos prácticos esto significa la guerra. Vitoria abrazs los antecedentes de guerra 
justa según habían sido fonrmulados por San Agustín y St. Tomás:

1. Debían hacerse por orden de la autoridad constituida, el príncipe.

2. Debían hacerse por una razón justa.

3. Los que van a la guerra deben tener una intención justa.

Como vemos no se dice mucho, pero Vitoria se va a hacer eco de esta tradición para establecer los títulos legítimos de intervención cuando se den las siguientes condiciones:

1. Que los indios atenten impedir el establecimiento de los españoles en las tierras indígenas.

2. Cuando la fuerza es necesaria para convertir a los indios.

3. Si un príncipe indio fuerza a sus súbditos a cometer Idolatría.

4. La intervención es permitida para defender a la gente inocente de los abusos de los príncipes indios.

5. Para apoyar a los aliados.

6. Cuando los indios se resisten a acatar el gobierno de la Corona española o actúan en contra de algunas de sus regulaciones.

Vitoria también define los títulos ilegítimos, o lo que es lo mismo, los límites del poder del Emperador y del Papa. El Emperador no debe ser considerado como el señor de todo el Orbe; el Papa no tiene poder terrenal sobre la población indígena; los aborígenes no deben ser forzados a convertirse a la religión cristiana; el Papa no tiene derecho de conceder poder secular a los Príncipes terrenales; la guerra no debe ser permitida para forzar a los indios a reconocer la Autoridad Papal; y finalmente, los indios no deben ser considerados culpables por el hecho de no tener religión cuando no han tenido ningún conocimiento previo del mensaje evangélico.

Una vez notadas las contradicciones patentes me gustaría analizar este último punto de que por la infidelidad tampoco se pierde el dominio y legítima autoridad, para mostrar coómo trabaja la mente de Vitoria. Así, para deshacer la confusión de las ideas medievales, Vitoria recurre al gran principio de St. Tomás que establece la neta distinción entre el orden natural y sobrenatural en el campo jurídico, disipando el falso Naturalismo latente en toda aquella concepción pseudoagustiniana del Orbis Christianus (por la que Cristo da su poder a la Iglesia; del Papa, en quien reside esta supremacía del poder espiritual y temporal, reciben su potestad los reyes. Dicha plenitud del poder papal se extiende, no sólo a la propiedad y todos los derechos de los infieles, sino también al dominio de los infieles). St. Tomás proclamaba (2-2 q. 10 a 10) que la infidelidad no destruye ningún derecho natural y humano, porque el derecho divino, que viene de la 
gracia, no anula el derecho humano, basado en la razón natural, es decir, "el derecho de gentes basado en la naturaleza". La distinción de creyentes e infieles nace del orden divino de la gracia, mientras que la propiedad privada y la autoridad civil han sido introducidas por el derecho natural y humano. De esta manera, los dominios de los paganos no se perderían por defecto de la fe.

Pues bien, si seguimos la doctrina tomista con todas sus consecuencias, no casa con lo que Vitoria nos está diciendo. Basándonos en la distinción que hace St. Tomás entre razón y fe, entre Filosofia y Teología, entre lo natural y lo divino, tendríamos que decir consecuentemente que razón y fe por supuesto no se hayan equilibradas en St. Tomás como dos facultades distintas de igual importancia, como pretende esconder Vitoria en su argumentación. Para el angélico cuando la razón no alcanza la fe, esto es, cuando la razón no puede probar los postulados de la fe, es porque, según dice St. Tomás, la razón presenta un error. La fe se halla por encima de la razón y la ordena a su fin que es Dios. Consecuentemente, siguiendo a St. Tomás podríamos defender el naturalismo agustinista del Orbis Christianus y la barbarie de los indios y su naturaleza de esclavos, como probadamente sostenía Aristóteles y por supuesto St. Tomás ${ }^{30}$. Vitoria se coloca en una posición vacilante y poco clara en la argumentación con la que intenta fundamentar teológicamente la conquista. Puede que el derecho divino no anule el humano-natural pero lo regula plenamente según lo expuesto.

La posesión de Vitoria es una posición de encrucijada donde S. Agustín y St. Tomás chocan; donde no se sabe cómo superar el Scotismo y el Ockhanismo Nominalista; donde no se sabe como integrar el humanismo; donde razón y fe parecen servir a distintos intereses. Efectivamente de lo que se trata es de un conflicto real de intereses entre papado y estado, nobles, súbditos, monjes, juristas, civiles intentando alcanzar señorio, distintas confesiones... conflictos de ung época de transición de la era medieval y el emergente Estado Modemo. La lucha particular de todas estas instituciones que van a poner su mirada en el indio es la desencadenante de ese nuevo espacio ontológico en el que se coloca Vitoria, una nueva fundamentación teológica-jurídica que ve al indio como un niño al que hay que educar en la fe para que logre su libertad (súbdito) y su salvación.

Lo que es más interesante en la argumentación de Vitoria acerca de la guerra justa descansa en las contradicciones irresolubles de su discurso ${ }^{31}$. Como hemos visto, de un lado los cristianos no tienen derecho de subyugar a los indios o de imponerles cualquier forma de gobierno, creencias o comportamientos, mientras por otro lado, la guerra es permitida cuando los indios atenten resistir la conversión, el gobiemo de la corona española o cualquiera de sus leyes ${ }^{32}$.

La única posible explicación de la existencia de tan Fragrantes contradicciones radica en que Vitoria al final falla al intentar proveer una sintesis de un sistema teológico sin conflictos con el cual explicar y justificar la empresa de colonización ${ }^{33}$. 
El que sí va a justificar la empresa en los años 1960 va a ser Teófilo Urdanoz, (el compilador de las obras completas de Vitoria) hablando de la evangelización y la conquista como "maravillosa singladura y empresa de siglos" en los siguientes términos:

"Maravillosa historia del éxodo de misioneros apostólicos desde las riberas del Tormes y de sus proezas de peregrinaciones y evangelización en las indias" 34 ... "Las Casas y su grupo doctrinal del partido misionero suplieron con creces la laguna de Vitoria, y en sus famosas disputas con los colonizadores perfilaron con toda claridad las nommas eternas de un justo gobierno colonial, cuya forma ideal plasmaron en las leyes de indias". ${ }^{35}$

Del mismo modo al referirse a la obra de Vitoria opina que:

"En 1543 se creó el admirable código de colonización cristiana por Vitoria que sería utilizado como base e inspiración por Las Casas en sus dieciséis remedios, siendo, la de Vitoria, la verdadera declaración de los derechos del hombre anterior en siglos a la revolución francesa"36... "el código más cristiano que jamás se ha promulgado en materia colonial, y gracias a él, cesaron las guerras de conquista, a las que sustituyeron la persuasión y predicación evangélica". ${ }^{37}$

Puede suponerse en este pensamiento un trasfondo de identificación y defensa de la política franquista, pero no lo voy a desarrollar por no ser el objetivo primordial de este trabajo.

Del mismo modo Hanke en una posición distinta señala en su introducción:

"Este libro se propone demostrar que la conquista de América no fue sólo una extraordinaria hazaña militar en la que un puñado de conquistadores sometió todo un continente en un plazo sorprendentemente corto de tiempo, sino, a la vez, uno de los mayores intentos que el mundo haya visto de hacer prevalecer la justicia y las normas cristianas en una época brutal y sanguinaria". ${ }^{38}$

Por otra parte, para autores como Subirats en los años 1990, Vitoria es "un humanista interesado en la expansión industrial y geográfica más que en el indio" 39 . Sea como fuere, los recurrentes silencios, vacios e inconsistencias epistemológicas presentes en la obra de Vitoria están motivadas por la imposibilidad de integrar la diversidad de sistemas teológicos y jurídicos desarrollados en el pensamiento renacentista en un omnicomprensivo corpus de doctrina.

Más allá del problema de la intencionalidad, Vitoria debe ser visto como un síntoma de época y el resultado del conflicto institucional de intereses que tienen parte en el proceso colonizador. Cuando se analizan los textos de Vitoria, el historiador necesita tener en mente el rol de la complejidad jugado por las formaciones discursivas e institucionales en los incipientes estadios de la moderni- 
dad, cuando el Estado Modemo está emergiendo y está trayendo consigo nuevos modos de establecer obediencia. Se necesita muchísimo trabajo de revisión de algunas de las líneas tradicionales de interpretación del pensamiento de Vitoria y su contribución al derecho internacional. Urdanoz y Hanke, revalorizando la teoría del dominico, establecen las bases para la justificación contemporánea de los procesos de violencia que tienen lugar en el siglo XVI en medio de la empresa de conquista. Futuras líneas de investigación necesitan abrir la tradición historiográfica a debate.

\section{Obras citadas:}

Foucault, Michael, Subject and Power. University of Chicago: Critical Inquiry 8 (Summer 1982).

Hanke, Lewis, La lucha por la justicia en la conquista de América. Trad. McAlister, Lyle N., Spain \& Portugal in the New World 1492-1700.

Minneapolis: University of Minnesota Press, 1984.

Maravall, J. A, La cultura del barroco. Barcelona: Ariel, 1975.

Estado Moderno y mentalidad social. Siglos XV - XVII. Madrid: Alianza editorial, 1972.

Navarro Cordón, J. M. \& Calvo Tomás, Historia de la filosofia, Madrid: ediciones Anaya S.A., 1982.

Subirats, Eduardo, El concilio vacio la conquista del nuevo mundo y la conciencia modema. Barcelona: Anaya \& Mario Muchnik, 1994.

Urdanoz, Teófilo, Obras de Francisco de Vitoria. Madrid: editorial católica, 1960.

Zamora, Margarita, Language, authority and indigenous historia in the comentarios reales de los Incas. Cambridge: Cambridge University. Pres, 1988.

1. Por "Nuevo Espacio Ontológico" entiendo aquí el movimiento que resulta en la creación de una nueva y moderna forma de ser, una nueva entidad o realidad como es la del Indio.

2. En una posible cuarta sección de este proyecto, me hubiera gustado discutir la posición de Teofilo Urdanoz, crítico y compilador de la obra de Vitoria en 1960, como un punto de vista que defiende y legitima la colonización en términos de un proceso inevitable y a la postre conmensurado por los designios divinos.

3. La manera en que enciendo el funcionamiento de las instituciones de poder como 
pera dos eparatos del Estado Moderno, encuentra puntos de contacto en la definidon que provee Michel Foucault: "It is certain that in contemporary societies the ande is not simply one of the forms of specific situations of the exercise of power even if it is the most important - but that in a certain way all others forms of power relation must refer to it. But this is not because they are derived from it; it is rather because power relations have come more and more under state control (although this state control has not taken the same form in pedagogical, judicial, economic, or family systems). In refering here to the restricted sense of the word", "government", one could say that the power relations have been progressively governmentalized, that is to say, elaborated, rationalized, and centralized in the form of, or under the auspices of, state institutions." Subject and Power.

La problemática del funcionamiento de las instituciones del Estado en las sociedades de la primera modernidad ha sido tratada por Maravall en la Cultura del Barroco y Estado Moderno y Mentalidad Social, donde propone modelos de interpretación de los productos culturales de la primera modernidad española sobre la base de su polimorfa relación con las estructuras de poder.

4. Te6filo Urdanoz Obras de Francisco de Vitoria, p.l.

5. Lewis Hanke, lucha por la justicia en la Conquista de América, p.252.

6. Teofilo Urdanoz Obras de Francisco de Vitoria, p.1300.

7. Ibid...

8. Vitoria, De la obligación a convertirse a Dios al llegar al uso de razón citado por Teofilo Urdanoz Obras de Francisco de Vitoria.

9. Ibid...p.1342

10. Ibid...p.1336: Como agrega Urdanoz: Lo que dicen los télogos: "Gracias a la providencia de Dios, no hay nación o provincia que ignore los preceptos del Derecho natural o el Decálogo si no es por Malicia [...]

" no hay ninguna nación tan cruel y tan bárbara que no crea en la existencia de Dios [...] Esta creencia fue conservada y admitida en todo el mundo después del diluvio ; luego no se olvidó tan completamente que no quedáse recuerdo".Como veremos contra todo esto reacciona Vitoria.

11. Ibid...pp.1342-1345.

12. Se habla de la imposibilidad de un conflicto real y definitivo entre los hallazgos de la razón y las exigencias de la fe cristiana. Todo conflicto aparente de ambas procederá o bien de errores de la razón, o bien de una deficiente interpretación de los contenidos de la fe religiosa. Aquino solamente tuvo en cuenta la primera posibilidad (el origen del conflicto se halla en los errores de la razón): es lógico que así fuera, dados los condicionamientos culturales de su época. Sin embargo una vez constituido el método científico a partir de la modernidad, los teólogos han optado a menudo por la segunda de las posibilidades propuestas (el origen del conflicto proviene de una interpretación deficiente de los contenidos de la fe cristiana): la intepretación de la Biblia se ha visto obligada a variar 
sustancialmente, especialmente en la teología protestante". Juan Manuel Navarro Cordón Tomás Calvo Martínez Historia de la filosofia, p. 112.

13. Vitoria De la obligación de convertirse a Dios al llegar al uso de razón en Teófilo Urdanoz Obras de Francisco de Vitoria, p. 1347.

14. Vitoria citado por Urdanoz en Obras de Francisco de Vitoria p. 515.

15. Maior, mestro de Vitoria, y Scoto, entre otros muchos como Sepúlveda, defendian la guerra evangelizante de manera clara acogiéndose a la teoría aristotélica de la "esclavitud natural". Maior: "por ello le es lícito a los príncipes cristianos sojuzgarles, ocupar sus tierras y someterles a efectiva servidumbre, a que por naturaleza están destinados. Cita de Urdanoz en Obras de Francisco de Vitoria, p. 499.

16. Teófilo Urdanoz Obras de Francisco de Vitoria, pp. 1297-1298.

17. Fray Pedro Juárez de Escobar as quoted in Robert Ricard The Spiritual Conquest of Mexico p. 150 as quoted by Lyle N. McAlister Spain \& Portugal in the new world 1492-1700, p. 172.

18. Vitoria's first step in "De indis" was to stablish a clear division between the natural and spiritual domains. Basic on the Thomistic distinction between these two orders Vitoria argued that every human being participates in the natural realm by virtue of his or her human nature, but only through a state of grace can one participate in the supernatural order, made accesible to mankind through Christ's redemptive intervention. Margarita Zamora, Language, authority and indegenous history in The Comentarios Reales de los Incas. p. 88.

19. Teófilo Urdanoz Obras de Francisco de Vitoria, p. 504.

20. "La actitud de Vitoria es en extremo favorable y respetuosa con los reyes de España sin la menor sombra de conflicto o protesta contra su conducta. Son gobernantes (Isabel, Fernando y Carlos V) tan Cristianos y rectos que en los problemas de ocupación de las Indias han obrado después de largos pareceres que les hayan dado seguridad de conciencia"...lbid p. 515.

21. Ibid... p. 55.

22. Nota: En relación con el problema de los fenómenos de centralización de la cultura en conexión con el desarrollo de espacios institucionalizados de mediación de las relaciones socio-políticas en el marco del incipiente estado modemo, véase Maravall Estado Moderno y Mentalidad Social y la Cultura del Bárroco.

23. Lewis Hanke Lucha por la justicia en la conquista de América, pp. 344; 349.

24. The question of the rationality of the american indigenes, however, remained very much alive and generated intense debate in Spain and the indies throughout discovery, conquest, and colonization. Generally speaking, steem for indians was highest among savants in Europe who had never seen one, lowest among officials and settlers who had to deal directly with their 
exasperating resistance to european ways. It must be said, however, that most spaniards in the new world had a vested interest in regarding indians as inferior beings. Lyle N. McAlister Spain and Portugal in the New World 1492-1700, p. 154.

25. Ibid... p. 172.

26. Resolución de Vitoria y otros teólogos en 1541 citado por Teófilo Urdanoz Obras de Francisco de Vitoria pp. 54-55.

27. Lewis Hanke Lucha por la justicia en la conquista de América, p. 278.

28. Historia general y natural de las indias, primera parte, lib. 1 cap. 6; lib. IV, cap. 2; lib. V y proemios 2 y 3; libro VI cap. 9 as qoted in Lewis Hanke The Spanish Struggle for Justicie in the Conquest of America, p. 11.

29. “...Vitoria hizo por medio del razonamiento lógico y sosegada exposición analítica todo lo que era posible hacer para salvar a los indios de América de la injusticia y la opresión y a él debe ir buena parte del crédito por el hecho de que un deseo de misericordia se convirtiese en rasgo central de la teoría colonial española. Es una de la ironías de la historia que un hombre mucho menos inteligente y mucho menos noble, Fray Barbolomé de Las Casas, el excesivamente elogiado "apóstol de los indios", lograra adueñarse de una gran parte del crédito que Vitoria debería haber recibido". Means The stanih main: focus of enry. p. 18.

30. El padre Gallegos se apoya en St. Tomás para defender la guerra justa contra los indios, tratado "De correctione fraterna" de St. Tomás, diciendo "si yo yerro también yerra St. Tomás" citado por Lewis Hanke Lucha por la justicia en la conquista de América, pp. 274-275.

31. "EN 1599 en Méjico Fray Alonso Martínez defendía la guerra justa con argumentos y citas de San Agustín, St. Tomás, el Ostiense, Aristóteles, Soto (principal discípulo de Vitoria) y otros muchos" citado por Ibid... pp. 292-293.

32. His ambivalence, moreover, is underlined by the predominant use of the conditional and subjunctive tenses. it it were true, he says, that the barbarious ere mentally deficient and therefore incapable of governing themselves as had been suggested, then it would be lict for the Spaniards to step in to stablish a legitimate government for the native's benefit. Thus, while Vitoria seemed to suggest that he favored the argument of the full capacity of the indians for self-rule and was extremely cautious in presenting the title based on their supposed incapacity in hypothetical terms ("parece no son idóneos para constituir y administrar una república legitima"), he nonetheless expressed serious doubts. It is precisely this persistent uncertainty about the nature of the indians of the New World which paved the way for the renowned debate between Las Casas and Sepúlveda, and ultimately Garcilaso's Comentarios Reales", Margarita Zamora Language, authority and indegenous history in The Comentarios Reales de los Incas pp. 90-91 y 
además veáse el comentario sobre los derechos legítimos que se hace en la p. 89.

33. “...Derecho propiamente indiano (corpus of law distinctively Spanish American) that had complex and contradictory characteristics. First, in spirit it was eminently casuistic, setting standars of behavior far beyond mortal capacity to meet and imposing an organic inflexibility on the whole. Second, the effort to give justice in each and every particular instance led to an inordinate concern with minutiae. Third, abstract principle and social reality formed a dialectic in which law became the synthesis. Finally, the dialectic along with the rapidity of legal formation led to numerous inconsistencies and contradictiosn between particular enactments. Taken together, these several qualities provide a constant templation to law evasion, an invitation to litigation, a paradise for lawers, andan impregnable refuge for bureaucrats "Lyle N. McAlisted Spanish \& Portugal in the New World 1492-1700, p. 184. Por otro lado, las leyes estaban dadas para instruir conducta más que para regularla p. 183.

34. Teófilo Urdanoz Obras de Francisco de Vitoria, p. 46.

35. Ibid... p. 495.

36. Ibid... p. 54 .

37. Ibid... p. 60.

38. Lewis Hanke Lucha por la justicia en la conquista de América, p. 13.

39. Eduardo Subirats El Continente Vacio, p. 50. 